\title{
Application of Distributed Optical Fiber Sensing Technology in the Anomaly Detection of Shaft Lining in Grouting
}

\author{
Chunde Piao, ${ }^{1}$ Jun Yuan, ${ }^{1}$ Bin Shi, ${ }^{2}$ Haijun Lu, ${ }^{3}$ Guangqing Wei, ${ }^{4}$ and Chunsheng Gu \\ ${ }^{1}$ Resources and Geosciences College, China University of Mining and Technology, Xuzhou, Jiangsu 221116, China \\ ${ }^{2}$ Department of Geo-Engineering \& Geo-Informatics, Nanjing University, Nanjing, Jiangsu 210023, China \\ ${ }^{3}$ Pingdingshan Coal Co., Ltd., Pingdingshan, Henan 467000, China \\ ${ }^{4}$ Suzhou Nanzee Sensing Technology Co., Ltd., Suzhou, Jiangsu 215123, China
}

Correspondence should be addressed to Chunde Piao; piaocd@126.com

Received 17 October 2014; Revised 1 February 2015; Accepted 2 February 2015

Academic Editor: Zhenhua Zhu

Copyright (C) 2015 Chunde Piao et al. This is an open access article distributed under the Creative Commons Attribution License, which permits unrestricted use, distribution, and reproduction in any medium, provided the original work is properly cited.

\begin{abstract}
The rupture of the shaft lining caused by grouting has seriously undermined the safety in coal mining. Based on BOTDR distributed optical fiber sensing technology, this paper studied the layout method of optical fiber sensors and the anomaly detection method of the deformation and obtained the evolution law of shaft deformation triggered by grouting. The research results showed that the bonding problem of optical fiber sensors in damp environment could be effectively solved, by applying the binder consisting of sodium silicate and cement. Through BOTDR-based deformation detection, the real-time deformation of the shaft lining caused by grouting was immediately spotted. By comparing the respective strain of shaft lining deformation and concrete deformation, the risk range of shaft lining grouting was identified. With the additional strain increment of the shaft lining triggered by each process of grouting, the saturated condition of grouting volume in strata was analyzed, providing an important technical insight into the field construction and the safety of the shaft lining.
\end{abstract}

\section{Introduction}

The shaft is like the throat of coal mine. The safety of the shaft itself is the basic foundation to ensure the normal operation of the whole mining activities [1]. The existing shafts deform due to many factors, such as the water loss of thick overburden and the high grouting pressure during the repair of shaft lining [2]. If an effective monitoring system is used in the shaft lining to timely identify the deformation during mining, the potential danger in the shaft lining will be noticed in advance, and effective measures can be taken to avoid serious accidents. At present, as to the monitoring methods of shaft deformation, the changes of strain at different horizons in the processes of shaft rupture have been analyzed, and the evolution mechanism of shaft lining fractures has been explored by installing conventional sensors (such as concrete strain meters [3]) and fiber Bragg grating strain sensors $[4,5]$ in the circumferential, vertical, and radial directions on the surface of shaft lining. Using a three-dimensional laser scanner and convergence measurements [6], the applicability of support patterns installed to control massive spalling during shaft sinking has been investigated and the selection flowchart of the concrete lining span has been proposed to control its severe damage prior to shaft excavation. But these sensors have many limitations, such as the poor anti-interference performance, the low integration degree, and the limited monitoring range. Therefore it is difficult for them to meet the requirement of shaft safety monitoring. In the aspect of recognition methods of grouting, ground penetrating radar [7], seismic reflection wave method [8], and some other methods have been applied. They can detect the changes of waveform, amplitude, and frequency before and after grouting and obtain the abnormal range behind shaft. The grouting effect inner rock body and reinforcement range have been identified by using microseismic monitoring technology [9] to detect the rock microcracks. These methods have some advantages, such as low cost and the macroscopical ability to grasp the structure of geological body. But they also 
entail many disadvantages, such as poor antielectromagnetic interference ability and the uncertainty as well as multiplicity in their detection results. As the frontier in the development of optical fiber sensing technology, distributed optical fiber sensing technology utilizes the one-dimensional characteristic of fiber geometry. Taking the measured parameters as a function of the fiber position, it can perform continuous measurement of the external physical parameters along the fiber geometric path in the entire length of optical fiber and can obtain the spatial distribution along with the timesensitive information of the measured physical quantity at the same time [10-13]. In distributed optical fiber sensing technology, the fiber is both the sensing medium and the transmission channel, which boasts many merits such as small size, light weight, adaptable geometry, antielectromagnetic interference, excellent insulating characteristic, high sensitivity, and applicability in far distance observation. Thus, it can be expected that distributed optical fiber sensing technology is the future of the new generation monitoring techniques [14-18].

With the progress of science and technology, the fundamental way to solve the problems in the shaft lining safety is to establish a modern, high-quality, completely reliable, and immensely sensitive monitoring method of deformation. By using BOTDR distributed optical fiber sensing technology, this paper studied the techniques in laying fiber sensors and the method of monitoring the grouting process. Through analyzing the vertical and circumferential deformation of the shaft lining caused by grouting, the research constructed an anomaly detection method of shaft lining in grouting based on distributed optical fiber sensing technology. Thus, the results of this study would provide the theoretical and technical support in identifying the features of deformation during the grouting process, which promoted the safe and effective exploitation of coal resources.

\section{BOTDR Distributed Detection and Anomaly Detection Method}

2.1. The Layout of Optical Fiber Sensors in Shaft Lining. The layout of optical fiber sensors has a direct impact on the detection performance. Therefore, on the basis of previous engineering applications of distributed optical fiber sensing technology in reinforced concrete beams [19], pile foundations [20], and tunnels [21, 22], the following layout method of shaft lining has been taken. On the concrete surface, the Ushaped groove with $3 \mathrm{~mm}$ width and $5 \mathrm{~mm}$ depth was made along the shaft lining. After dusts were removed in the Ushaped groove, the single mode fiber of a diameter of $0.9 \mathrm{~mm}$ was laid. The binder combined with sodium silicate $\left[\mathrm{Na}_{2} \mathrm{O}\right.$. $\left.\mathrm{n}\left(\mathrm{SiO}_{2}\right)\right]$ and cement was filled into the groove to ensure the uniform deformation of the shaft lining and the fiber. The $5 \mathrm{~m}$ long sensing fiber was reserved under special protection during installation and was connected to the transmission cable later.

When monitoring the deformation in the certain range of depth, the four-core cable with sheath was placed in the fiber laying position along the shaft lining surface from the ground

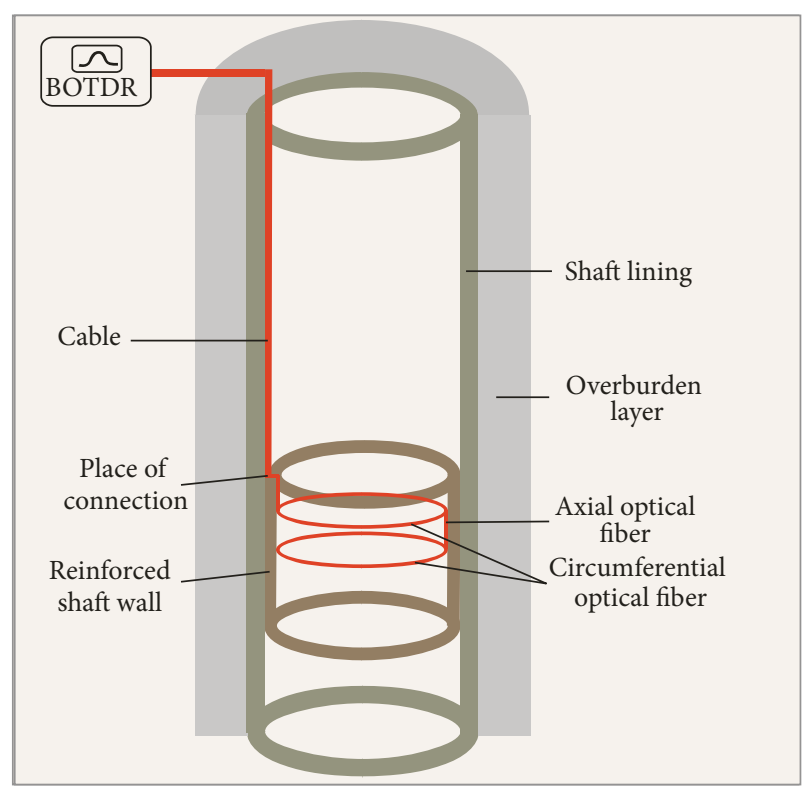

FIGURE 1: Schematic diagram of the sensing fiber layout.

and got fused with the sensing fiber reserved previously, and the other end of the cable on the ground was connected with BOTDR. In order to prevent the damage of the optical fiber sensors during shaft lining construction and operation, the metal bellows were used to enwrap the connection part. And the related schematic diagram of the sensing fiber layout is shown in Figure 1.

\subsection{Distributed Detection Method of Shaft Lining in Grout-} ing. Before grouting, such parameters as the testing scope, frequency and precision, which BOTDR would test, were set according to the shaft depth and detection requirements. At the same time, the deformation was measured as the initial value. With the number of times or the amount of grouting as the unit, we monitored the shaft lining deformation caused by grouting and subtracted the deformation in a certain frequency from the initial value as the shaft lining additional strain. The spatial location of the shaft lining deformation was calculated, according to the distance between BOTDR and Brillouin scattering light which returned through the fiber from a point, as is shown as follows:

$$
Z=\frac{c \cdot T}{2 n},
$$

where $Z$ is the distance between force bearing point along the sensing fiber line and the input end of BOTDR; $c$ is the speed of light in vacuum; $T$ is the time interval between the emitted pulsed light and the receiving Brillouin scattered light which returns from the force bearing point; and $n$ is the refraction coefficient of the optical fiber.

\subsection{The Anomaly Detection Method of the Shaft Lining} Deformation in Grouting. Through the buried fiber sensors, the grouting-triggered additional strain was detected in the vertical and circumferential directions and was compared 
TABLE 1: Main aquifers that the shaft crosses.

\begin{tabular}{lccccc}
\hline Layer & Thickness $(\mathrm{m})$ & Aquifer thickness $(\mathrm{m})$ & Aquifer type & Static water level $(\mathrm{m})$ & $\begin{array}{c}\text { Estimated water } \\
\text { inflow }(\mathrm{m} / \mathrm{h})\end{array}$ \\
$\begin{array}{l}\text { The Quaternary } \\
\begin{array}{l}\text { Liujiagou group of } \\
\text { Triassic sandstone }\end{array}\end{array}$ & 289 & 50 & Confined pore water & +120.52 & 63.89 \\
\hline $\begin{array}{l}\text { The Permian } \\
\begin{array}{l}\text { Shiqianfeng } \\
\text { formation + first } \\
\text { division sandstone }\end{array}\end{array}$ & 262.5 & 159 & $\begin{array}{c}\text { Porous-fractured } \\
\text { water }\end{array}$ & +150.28 & 762.78 \\
$\begin{array}{l}\text { The Permian coal } \\
\text { stratum }\end{array}$ & 521 & 168.7 & $\begin{array}{c}\text { Porous-fractured } \\
\text { water }\end{array}$ & +149.38 & 176.93 \\
\hline
\end{tabular}

with the circumferential yield strain $\varepsilon_{s}$ and the circumferential failure strain $\varepsilon_{k}$, based on which the risk zones of shaft lining deformation were found [23]. The evaluation index $\tau$ of shaft lining deformation is illustrated as

$$
\tau= \begin{cases}\varepsilon \leq \varepsilon_{s} & \text { Shaft lining safety } \\ \varepsilon_{s}<\varepsilon \leq \varepsilon_{k} & \text { Shaft lining damage } \\ \varepsilon>\varepsilon_{k} & \text { Shaft lining fracture }\end{cases}
$$

The additional strain increment upon the shaft lining resulting from each process of grouting can be calculated by

$$
\Delta \varepsilon=\varepsilon_{i+1}-\varepsilon_{i}
$$

where $\varepsilon_{i}$ and $\varepsilon_{i+1}$ are the respective deformation volume of the shaft lining after the $i$ and the $i+1$ time of grouting.

With the additional strain increment obtained from (3), the filling condition of slurry on shaft was analyzed. In order to ensure the shaft lining safety, the uniform deformation of the stress region was adjusted to reinforce the overburden layer around shaft lining and to seal off the aquifer, through taking such control measures as stopping grouting, slowing grouting, changing grouting hole or grouting horizon, and so on.

\section{Project Example and Data Analysis}

3.1. Project Background. The project discussed in this paper locates at a coal mine of Pingdingshan Coal Co. Ltd. in Henan province. With the freezing method adopted in construction, its lining was double reinforced concrete shaft lining with the design diameter of $6.5 \mathrm{~m}$. The shaft wall thickness in the 0-393.6 m section was $1050 \mathrm{~mm}$; in the $393.6-520 \mathrm{~m}$ section, $700 \mathrm{~mm}$; in the $520-676 \mathrm{~m}$ section, $800 \mathrm{~mm}$; and in the $676-$ $1075 \mathrm{~m}$ section, $500 \mathrm{~mm}$. The concrete strength of the shaft lining within the depth of $420 \mathrm{~m}$ was C50 and below the depth of $420 \mathrm{~m}$ was C70. According to the data of the existing exploration hole and the real strata conditions, it can be found that the strata mainly consist of clastic rock, and the aquifers mainly consist of multilayer sandstone. The main aquifers crossed by the shaft lining are shown in Table 1.

Under the normal construction of the shaft lining, there are close hydraulic connections between Liujiagou formation and the Pingdingshan formation. Influenced by the "surrounding rock loose circle," the backwall sand layer bears the high water pressure [24]. Based on the Pingdingshan coal mining districts' geological conditions and the features of water disasters in the aquifer, backwall grouting for blocking water was conducted in line with the construction design. But during the repair of shaft lining grouting, a $0.6 \mathrm{~m}$ diameter hole appeared at the depth of $589 \mathrm{~m}$ plane in the direction of $23^{\circ}$ north by west, because of the high grouting pressure. With the high water pressure upon the backwall, a large amount of sand body rushed into the shaft wall, resulting in the shaft lining fracture and damage from $587 \mathrm{~m}$ to $605 \mathrm{~m}$. In order to strengthen it, the shaft lining from $580 \mathrm{~m}$ to $610 \mathrm{~m}$ was reinforced with another wall, making the net diameter of the new shaft lining increase to $6.2 \mathrm{~m}$.

Water infiltrated the new shaft lining because of the high dynamic water pressure upon the shaft backwall, which undermined the safety of the shaft lining. To solve the problem, we put two circumferential sensing optical fibers at the depth of $582.5 \mathrm{~m}$ plane and $590 \mathrm{~m}$ plane and put the vertical sensing optical fiber which crossed the two circumferential sensing optical fibers in the direction of $35^{\circ}$ north by west, at the depth between $582.5 \mathrm{~m}$ and $590 \mathrm{~m}$. After that, the meeting points of sensing optical fibers were fused with each other and the series sensing optical fibers were then fused with the transmission cable which was put at the detection position. And the other end of the cable was connected with BOTDR strain analyzer, testing the shaft lining deformation caused by grouting. The laying method of sensing fibers and the monitoring of shaft are shown in Figure 2.

3.2. Repair of Shaft Lining Grouting. The grouting process can be divided into two parts, according to the shaft lining's additional strain and the seepage condition. First, cement was grouted behind the concrete shaft lining between the depths of $280 \mathrm{~m}$ to $290 \mathrm{~m}$. Secondly, chemical grouting was conducted into the spaces between the concrete of the shaft lining. The grouting location and grouting volume of shaft lining are given in Table 2.

3.3. Analysis on Detection Results of Grouting. The circumferential strain distribution of shaft lining caused by each 


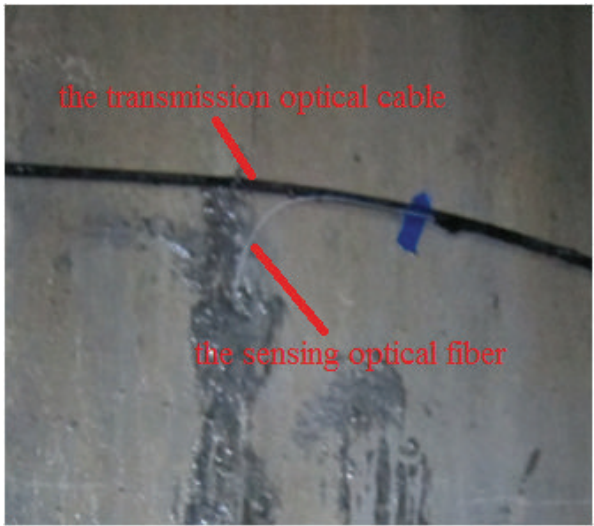

(a) Connection of the sensing optical fibers

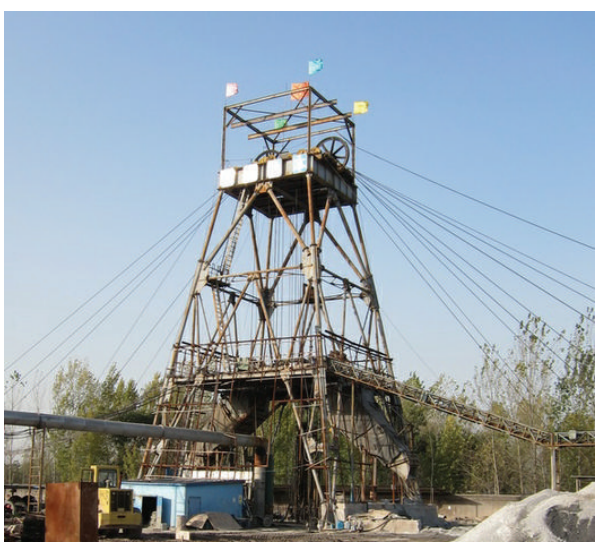

(c) Shaft detecting site

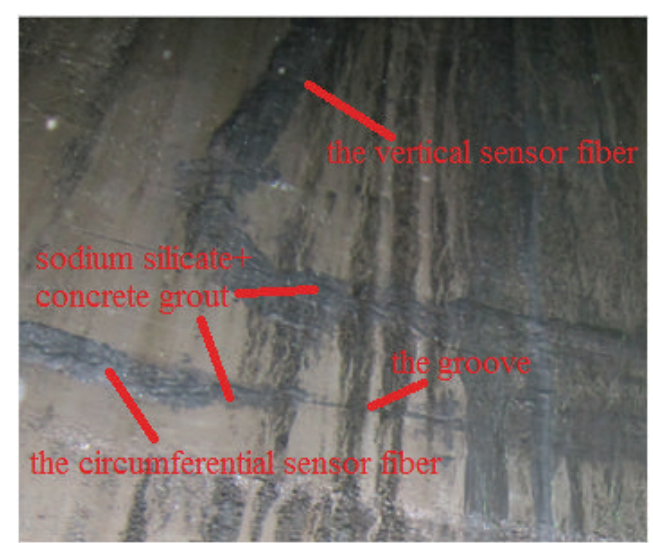

(b) Layout of the sensing optical fibers

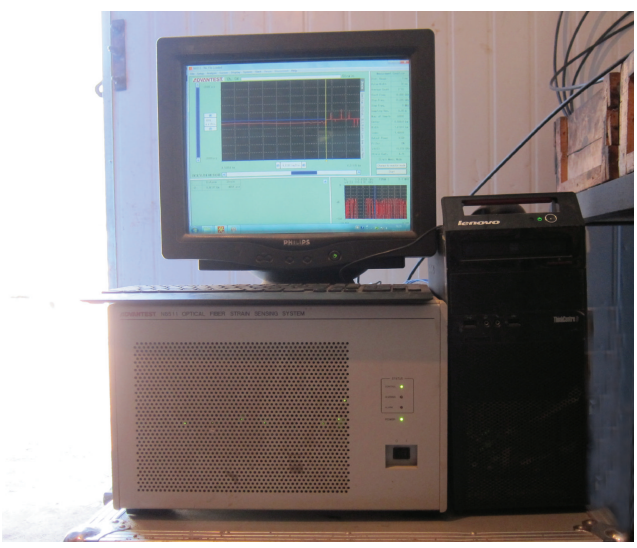

(d) BOTDR interrogator

FIGURE 2: Installation of the monitoring systems in the field.

TABLE 2: Grouting process of shaft lining.

\begin{tabular}{|c|c|c|}
\hline \multicolumn{2}{|c|}{ Grouting step numberGrouting location (m) } & $\begin{array}{c}\text { Grouting amount } \\
\left(\mathrm{m}^{3}\right)\end{array}$ \\
\hline \multirow[t]{2}{*}{1} & $280-285$ & \multirow{2}{*}{2 (cement grouting) } \\
\hline & $288.5-292.5$ & \\
\hline \multirow{2}{*}{2} & $282.5-285$ & \multirow{2}{*}{1.5 (cement grouting) } \\
\hline & 288.5-292.5 & \\
\hline \multirow{2}{*}{3} & $282.5-285$ & \multirow{2}{*}{1.5 (cement grouting) } \\
\hline & $287.5-288$ & \\
\hline 4 & $282.5-285$ & 1 (cement grouting) \\
\hline \multirow{2}{*}{5} & $282.5-285$ & \multirow{2}{*}{1 (cement grouting) } \\
\hline & $287.5-290$ & \\
\hline \multirow{2}{*}{6} & $282.5-285$ & \multirow{2}{*}{1 (cement grouting) } \\
\hline & $287.5-290$ & \\
\hline 7 & $280-290$ & $\begin{array}{l}0.77 \text { (chemical } \\
\text { grouting) }\end{array}$ \\
\hline 8 & $280-290$ & $\begin{array}{l}0.83 \text { (chemical } \\
\text { grouting) }\end{array}$ \\
\hline
\end{tabular}

process of grouting was obtained by the two circumferential sensing optical fibers at the depth of $582.5 \mathrm{~m}$ and $590 \mathrm{~m}$, as shown in Figures 3 and 4 . The strain distributions were the strains that expanded in anticlockwise order from the starting point of the north direction. After expansion, the circumference of shaft lining was $19.468 \mathrm{~m}$.

As shown in Figures 3 and 4, the deformation of shaft lining had a larger fluctuation caused by grouting. The additional strain distribution at position of $0 \mathrm{~m}$ and $3.7 \mathrm{~m}$ in Figure 3 and the positions of $0 \mathrm{~m}, 3.7 \mathrm{~m}$, and $16.2 \mathrm{~m}$ in Figure 4 showed that the compression strain value in circumferential directions was larger and the stress state presented the obvious feature of regionality. The main reason was that, affected by the early stage of shaft lining fracture, many cavities appeared in the shaft lining behind the shaft rock wall at position of $589 \mathrm{~m}$ plane in the direction of $23^{\circ}$ north by west. These cavities were firstly filled by the slurry when injecting the cement slurry. The shaft lining gradually produced the inward deformation caused by grouting and the compression strain value in circumferential directions gradually increased. The main influence range of cement slurry concentrated upon the grouting region of grouting holes because of high viscosity, large granules, and short diffusion distance. The additional strain of the slurry which flowed through the void and fracture behind the shaft sandstone gradually increased due to the influence of surrounding 


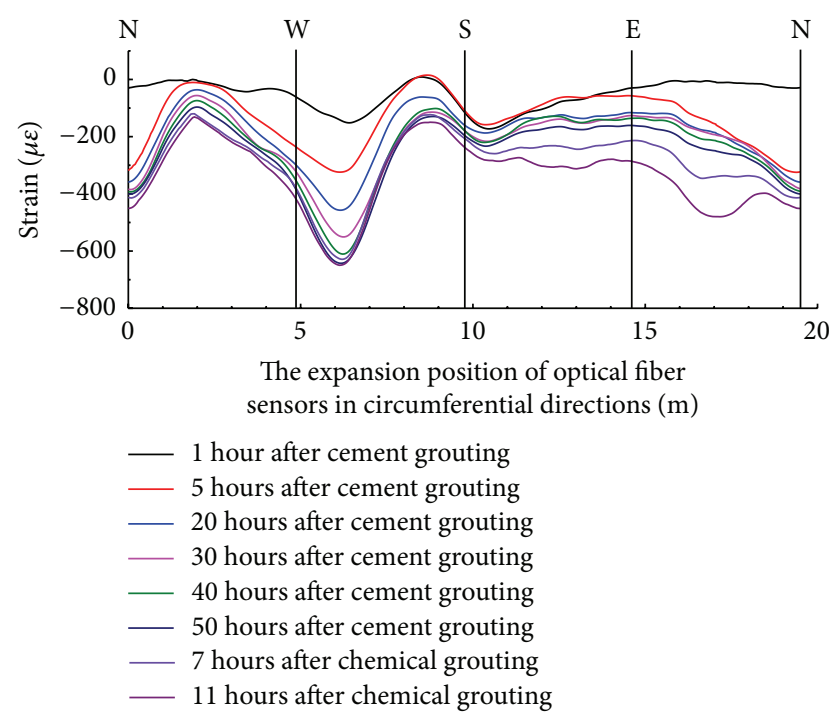

FIGURE 3: The circumferential strain distribution of shaft lining at the depth of $582.5 \mathrm{~m}$ plane.

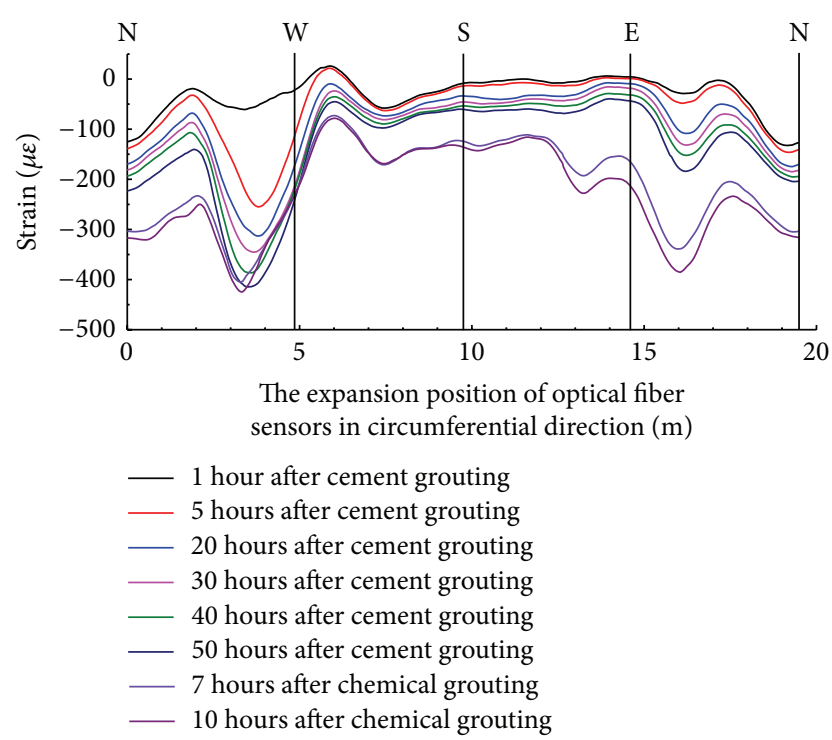

FIgURE 4: The circumferential strain distribution of shaft lining at the depth of $590 \mathrm{~m}$ plane.

rock loose circle when injecting the cement slurry into the shaft lining behind the shaft rock wall. That is to say, the circumferential deformation was relevant to the range of rock loose circle behind the shaft rock wall and the grout amount.

The strain value in circumferential directions increased evenly and the slurry spread to the surrounding far distance as the center of grouting holes when injecting chemical grout between the shaft rock wall based on the advantages of highquality grouting, low viscosity, and excellent impermeability. The additional strain distribution on the range of $0-5.2 \mathrm{~m}$ in Figure 3 and the range of $2.5-5.5 \mathrm{~m}$ in Figure 4 shows that the void of double-layer shaft wall was compressed gradually caused by grouting using the cement slurry while

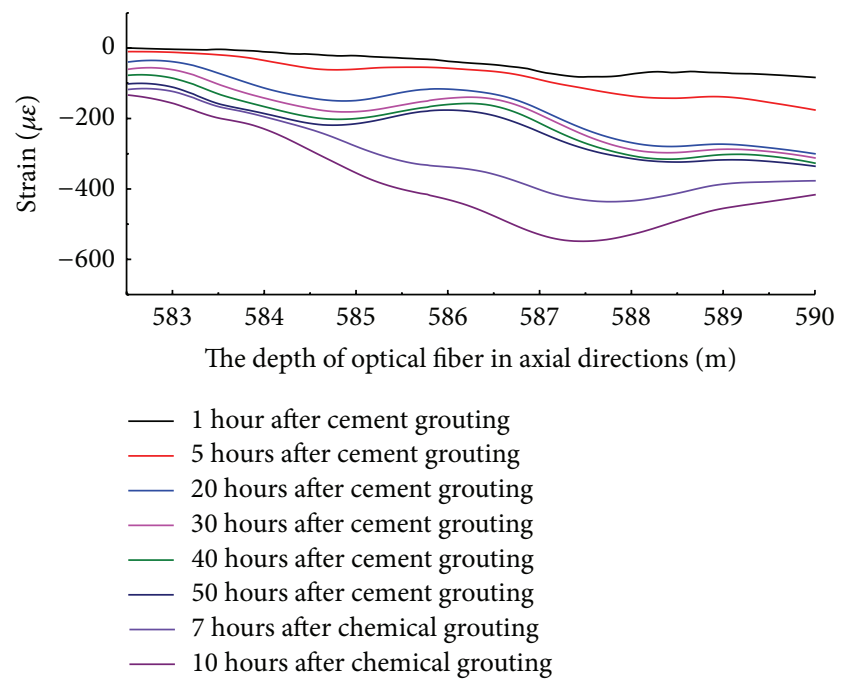

FIgURE 5: The additional strain distribution of the shaft lining in axial directions.

less deformation of the shaft lining was caused by chemical grouting. The additional strain distribution on the range of $10-19.5 \mathrm{~m}$ in Figure 3 and the range of $5.5-19.5 \mathrm{~m}$ and $0-2.5 \mathrm{~m}$ in Figure 4 shows that the deformation of the shaft lining caused by grouting using cement slurry was comparatively smaller. At this time, the grouting of chemical grout increased and the deformation of the shaft lining became larger with the grouting capacity of chemical grout increasing.

The additional strain value of the shaft lining in axial directions caused by grouting is as shown in Figure 5 .

As shown in Figure 5, the additional strain on the range of $582.5-587 \mathrm{~m}$ was essentially consistent when injecting cement slurry into the shaft lining. The reason was that the strengthening area of surrounding soil caused by grouting in axial directions was uniform. The grouting capacity near the depth of $589 \mathrm{~m}$ plane increased due to the influence of the previous shaft lining fracture and caused the compressive strain in which the surrounding soils acted on the shaft lining increasing. So the additional strain on the depth between $587.5 \mathrm{~m}$ and $590 \mathrm{~m}$ increased. The compression strain on the depth between $585 \mathrm{~m}$ and $587.5 \mathrm{~m}$ in axial directions increased rapidly when injecting chemical grout between the shaft rock wall. There were mainly two reasons behind this phenomenon. On the one hand, deformation of the shaft lining at the depth between $585 \mathrm{~m}$ and $587.5 \mathrm{~m}$ was small caused by cement slurry and the void was filled by chemical grout. On the other hand, the shaft lining at the depth between $575.5 \mathrm{~m}$ and $590 \mathrm{~m}$ was damaged seriously because of pregrouting pressure. The strengthening area of cement slurry mainly concentrated near the grouting holes, and away from the grouting holes, the fracture existed in the shaft lining. With chemical grout injecting into the shaft lining behind the shaft rock wall along the fracture plane, the section of shaft lining was reinforced effectively.

According to the actually measured data, the yield strain of high strength concrete in circumferential directions was $-1400 \mu \varepsilon$ and the fracture strain in circumferential directions 


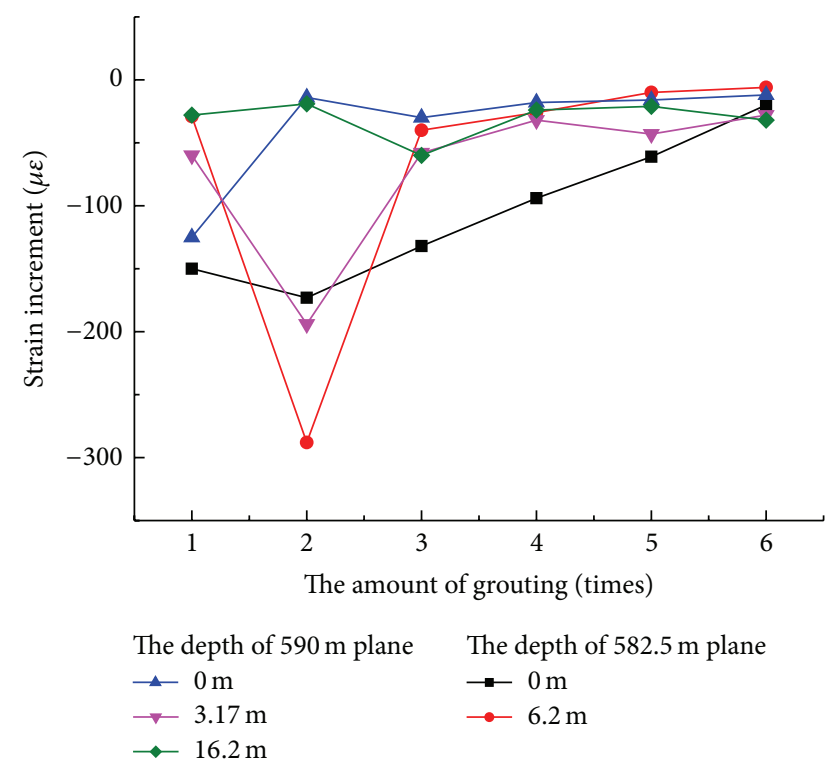

FIGURE 6: The relationship between the amount of grouting using cement slurry and the strain increment in circumferential directions.

was $-3400 \mu \varepsilon[25,26]$. The maximum strain of shaft lining caused by grouting in circumferential directions was $-648 \mu \varepsilon$ caused by grouting. As shown in (2), the maximum strain was smaller than the yield strain in circumferential directions. The results showed that the concrete shaft lining was in safe conditions.

In order to understand the evolution characters of shaft lining caused by grouting behind the shaft rock wall using cement slurry, several strain values with larger deformation were chosen in the distribution curve of the upper and lower optical fiber sensors in circumferential directions. The strain increment in circumferential directions caused by grouting was calculated by (3), as shown in Figure 6.

As shown in Figure 6, the additional strain increment was volatile due to the influence of sand layers structure at the beginning of grouting. The slurry volume injected into the grouting holes gradually reduced and the strain increment of the shaft lining gradually turned to be consistent and stable with the amount of grouting increasing. It showed that the voids in sandstone were replaced by slurry and slurry volume had reached the saturation point. The above analysis shows that the change of slurry volume and the deformation of shaft lining can be detected effectively in grouting based on the distributed optical fiber sensing technology.

\section{Discussions}

(1) The binder, made of epoxy and curing agent, was used to glue the optical fiber sensors on structures, such as tunnels and pile foundations $[27,28]$, but this binder was more suitable for structures with dry surfaces, because the adhesive strength would be too small when used on damp surfaces. As for the shaft lining which needs grouting, the surface of some part of the shaft lining was seeping or flowing with water due to the deep burial depth and a close connection between the sidewall and the surrounding aquifer. The binder, made of the sodium silicate and concrete, is characterized by faster consolidation speed and higher adhesive strength, so it can make the fiber sensor and the shaft lining bond together, which will effectively solve the problems caused by the seeping water.

(2) The repair of shaft lining is faced with such hidden dangers as the problem of shaft lining crack caused by the high-pressure grouting, and the problem of watergushing and sand-gushing resulted from overflowing serosity along the shaft lining crack [29]. So far, the traditional detection methods of grouting effects include rock coring, sonic testing, and electromagnetic method [2]. Nevertheless, grouting response of the shaft lining is a dynamic process; the static methods mentioned above fail to measure the realtime deformation during the process of grouting. Traditional detection methods, which install stress meter or stress gauge in several monitoring places on the shaft lining, cannot comprehensively record the entire deformation, leading to some damages undetected [29]. By comparison, the BOTDRbased detection method, through the circumferentially and axially laid sensing optical fiber, can establish the shaft deformation monitoring network and detect the additional strain caused by grouting, validate the abnormal area and value of the additional strain, obtain the impact of the ground disturbance upon the shaft lining deformation, and reveal the distribution of serosity along cracks and fracture of the ground. Therefore, this method can effectively guide the informative construction during the grouting process, which guarantees the safety of the shaft lining.

\section{Conclusions}

(1) In view of the seepage in the grouting segment of shaft lining, the binder, made of sodium silicate and cement, can effectively solve the bonding problem of the sensing fiber in the damp environment. Considering the structure and deformation characteristic of shaft lining, this study puts forward the layout methods of the sensing fiber, including grooving, Actinobacillus, and filling binder.

(2) This research constructed the methods of data detection and data processing during grouting and established the distributed detection method of the deformation of shaft lining in grouting, through the axial and circumferential sensing fiber laid in the shaft lining. Based on the experimental example of grouting, it has been found that the distributed optical fiber detection method can effectively identify the grouting condition in the serosity and can offer a new method for the anomaly detection of grouting quantity, thus reinforcing the safety of the shaft lining.

(3) The cement grouting and the chemical grouting act as an interactive system in fixing the shaft lining. Through the distributed detection of the grouting process, the study analyzed the additional strain on the shaft lining caused by each process of grouting and obtained the "saturated" condition of the grouting capacity in the strata. With the advantages of high intensity and high durability in cement slurry and the merits of low viscosity in chemical grout, 
the combination of these two methods promoted a uniform deformation in the grouting segment of the shaft lining, which not only could effectively block the leakage problem of the shaft lining but also would prevent the shaft lining from rupturing triggered by concentrated stresses.

\section{Conflict of Interests}

The authors declare that there is no conflict of interests regarding the publication of this paper.

\section{Acknowledgments}

The work is funded by National Science Foundation for Youth (no. 51004103), China Postdoctoral Science Foundation (no. 20100481175), and the Priority Academic Program Development of Jiangsu Higher Education Institutions.

\section{References}

[1] H. Q. Liang, G. S. Zhao, and H. C. Liang, "Theory and practice in the control of shaft-lining rupture through soil grouting," China Safety Science Journal, vol. 19, no. 1, pp. 5-9, 2009.

[2] H.-C. Xia and M.-A. Tang, "Mechanism and application of grouting into topsoil to prevent shaft lining from fracturing," Journal of Mining and Safety Engineering, vol. 26, no. 4, pp. 407412, 2009

[3] X. D. Zhang, Y. R. Han, S. J. Liu, and C. S. Su, "Deformation prediction analysis model for the mine shaft-wall," Journal of Liaoning Technical University (Natural Science), vol. 33, no. 8, pp. 1070-1073, 2014.

[4] C. Zhang, W. H. Yang, J. G. Qi, H. P. Li, and T. Zhang, “Construction technology and monitoring analysis of a new singlelayer shaft lining in deep aqueous bedrock during freezing sinking," Chinese Journal of Rock Mechanics and Engineering, vol. 31, no. 2, pp. 337-346, 2012.

[5] H.-C. Liang, G.-Q. Zhou, G.-S. Zhao, and B. Liao, "Strain characters of shaft lining crack," Journal of the China Coal Society, vol. 35, no. 2, pp. 198-202, 2010.

[6] K. Tsusaka, D. Inagaki, M. Nago, K. Kamemura, M. Matsubara, and M. Shigehiro, "Relationship between rock mass properties and damage of a concrete lining during shaft sinking in the horonobe underground research laboratory project," in Proceedings of the World Tunnel Congress: Underground-The Way to the Future (WTC '13), G. Anagnostou and H. Ehrbar, Eds., pp. 2014-2021, June 2013.

[7] D. M. Pan, H. Zhang, and X. J. Zhao, "Application of ground radar tom ine shaft liner grouting and result inspection," Coal Science and Technology, vol. 35, no. 2, pp. 24-26, 2007.

[8] P.-S. Zhang and L.-Q. Guo, "Detection technology by reflection wave for backwall grouting quality of a vertical shaft," Journal of Mining \& Safety Engineering, vol. 28, no. 1, pp. 115-121, 2011.

[9] N. W. Xu, C. A. Tang, L. C. Li et al., "Microseismic monitoring and stability analysis of the left bank slope in Jinping first stage hydropower station in southwestern China," International Journal of Rock Mechanics and Mining Sciences, vol. 48, no. 6, pp. 950-963, 2011.

[10] M. Kihara, K. Hiramatsu, M. Shima, and S. Ikeda, "Distributed optical fiber strain sensor for detecting river embankment collapse," IEICE Transactions on Electronics, no. 4, pp. 952-960, 2002.
[11] K. Komatsu, K. Fujihashi, and M. Okutsu, "Application of optical sensing technology to the civil engineering field with optical fiber strain measurement device (BOTDR)," in Advanced Sensor Systems and Applications, vol. 4920 of Proceedings of SPIE, pp. 352-361, 2002.

[12] H. Ohno, H. Naruse, T. Kurashima, A. Nobiki, Y. Uchiyama, and Y. Kusakabe, "Application of Brillouin scattering-based distributed optical fiber strain sensor to actual concrete piles," IEICE Transactions on Electronics, no. 4, pp. 945-951, 2002.

[13] H. Ohno, H. Naruse, M. Kihara, and A. Shimada, "Industrial applications of the BOTDR optical fiber strain sensor," Optical Fiber Technology, vol. 7, no. 1, pp. 45-64, 2001.

[14] N. Yasue, H. Naruse, J.-I. Masuda, H. Kinq, T. Nakamura, and T. Yamaura, "Concrete pipe strain measurement using optical fiber sensor," IEICE Transactions on Electronics, no. 3, pp. 468474, 2000.

[15] H. Naruse, Y. Uchiyama, T. Kurashima, and S. Unno, "River levee change detection using distributed fiber optic strain sensor," IEICE Transactions on Electronics, no. 3, pp. 462-467, 2000.

[16] H.-H. Zhu, J.-H. Yin, L. Zhang, W. Jin, and J.-H. Dong, "Monitoring internal displacements of a model dam using FBG sensing bars," Advances in Structural Engineering, vol. 13, no. 2, pp. 249-261, 2010.

[17] H.-H. Zhu, A. N. L. Ho, J.-H. Yin, H. W. Sun, H.-F. Pei, and C.-Y. Hong, "An optical fibre monitoring system for evaluating the performance of a soil nailed slope," Smart Structures and Systems, vol. 9, no. 5, pp. 393-410, 2012.

[18] H.-H. Zhu, B. Shi, J.-F. Yan, J. Zhang, C.-C. Zhang, and B.J. Wang, "Fiber Bragg grating-based performance monitoring of a slope model subjected to seepage," Smart Materials and Structures, vol. 23, no. 9, Article ID 095027, 2014.

[19] J. Q. Gao, B. Shi, W. Zhang, D. Zhang, and H. Zhu, "An experimental study for measuring the distributed strain of reinforced concrete beam using BOTDR," China Civil Engineering Journal, vol. 38, no. 9, pp. 74-79, 2005.

[20] C.-D. Piao, B. Shi, G.-Q. Wei, Y.-Q. Zhu, and D. Zhang, "Application of distributed fiber optic sensing techniques in bored pile detection," Chinese Journal of Geotechnical Engineering, vol. 30, no. 7, pp. 976-981, 2008.

[21] B. Shi, H. Xu, B. Chen et al., "A feasibility study on the application of fiber-optic distributed sensors for strain measurement in the Taiwan strait tunnel project," Marine Georesources and Geotechnology, vol. 21, no. 3-4, pp. 333-343, 2003.

[22] Y.-S. Wang, W.-H. Yang, J.-H. Huang, L. Song, and Y.-L. Ren, "Study of freeze sinking period concrete strain of outer shaft wall of Longgu Coal Mine auxiliary shaft," Journal of the China Coal Society, vol. 31, no. 3, pp. 296-300, 2006.

[23] Z.-W. Qian, Z.-Q. Jiang, L.-W. Cao, and Q. Sun, "Research on backfill grouting based on surrounding rock loose circle theory," Journal of the China Coal Society, vol. 38, no. 2, pp. 189-193, 2013.

[24] J. Wu and W. W. Qian, "Horizontal ultimate bearing capacity test of high strength reinforced concrete shaft lining," Journal of Anhui University of Science and Technology (Natural Science), vol. 32, no. 4, pp. 56-59, 2012.

[25] T. Han, W.-H. Yang, Y.-L. Ren, and Z.-J. Yang, "Horizontal ultimate bearing capacity of encased steel concrete shaft lining," Journal of Mining and Safety Engineering, vol. 28, no. 2, pp. 181186, 2011.

[26] D. Zhang, B. Shi, and H. Z. Xu, "The BOTDR-based strain monitoring for tunnel," Journal of Engineering Geology, vol. 12, no. 4, pp. 422-426, 2004. 
[27] G.-Q. Wei, B. Shi, J.-X. Jia, S. Hu, K. Li, and D. Zhang, "Application of distributed optical fiber sensing to testing inner force of prefabricated piles," Chinese Journal of Geotechnical Engineering, vol. 31, no. 6, pp. 911-916, 2009.

[28] H.-L. Fu, "Strain variation regularity of shaft lining during grouting reinforcement process for deep topsoil ground," Rock and Soil Mechanics, vol. 24, pp. 21-23, 2003.

[29] G.-Q. Zhou, Y.-Z. Liu, X.-W. Feng, and G.-S. Zhao, "Application and effect of grouting in surrounding soil on releasing and restraining additional stress of shaft lining," Chinese Journal of Geotechnical Engineering, vol. 27, no. 7, pp. 742-745, 2005. 

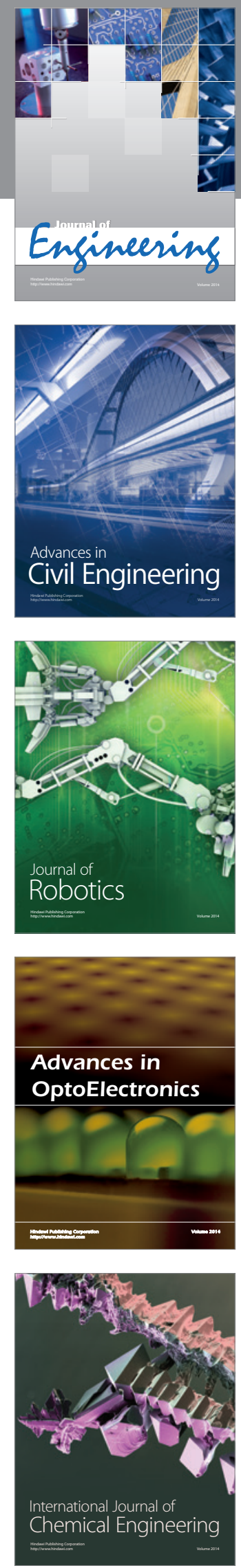

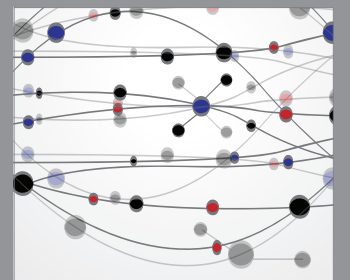

The Scientific World Journal
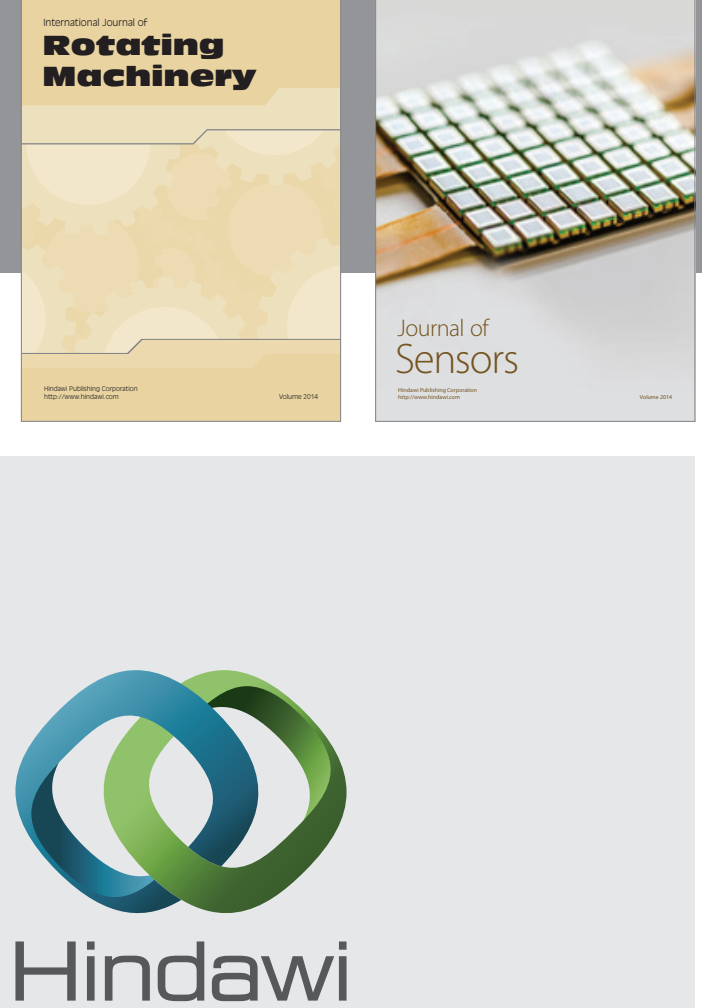

Submit your manuscripts at http://www.hindawi.com
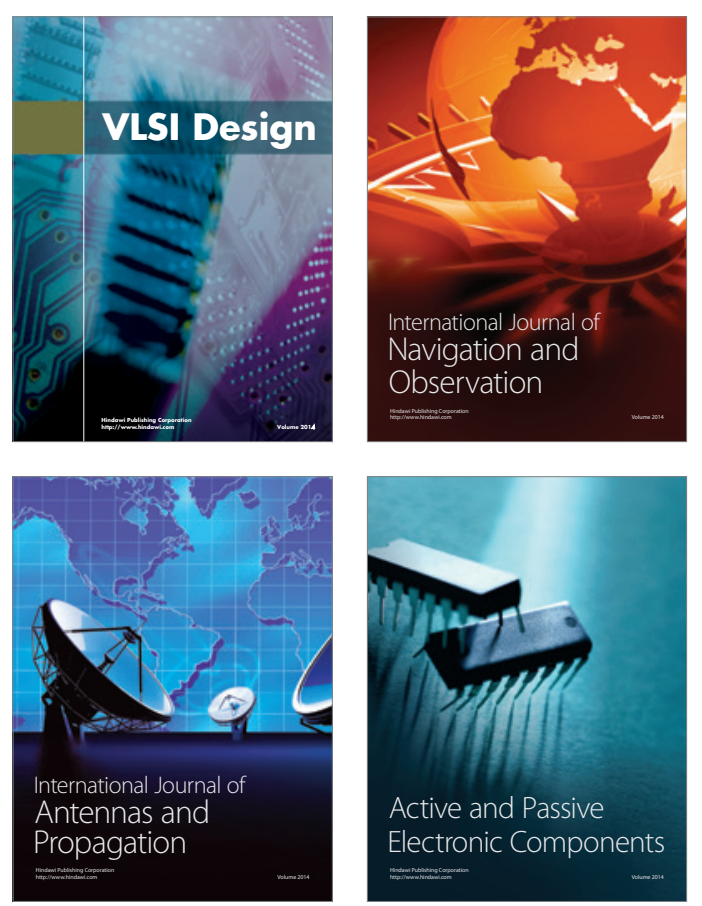
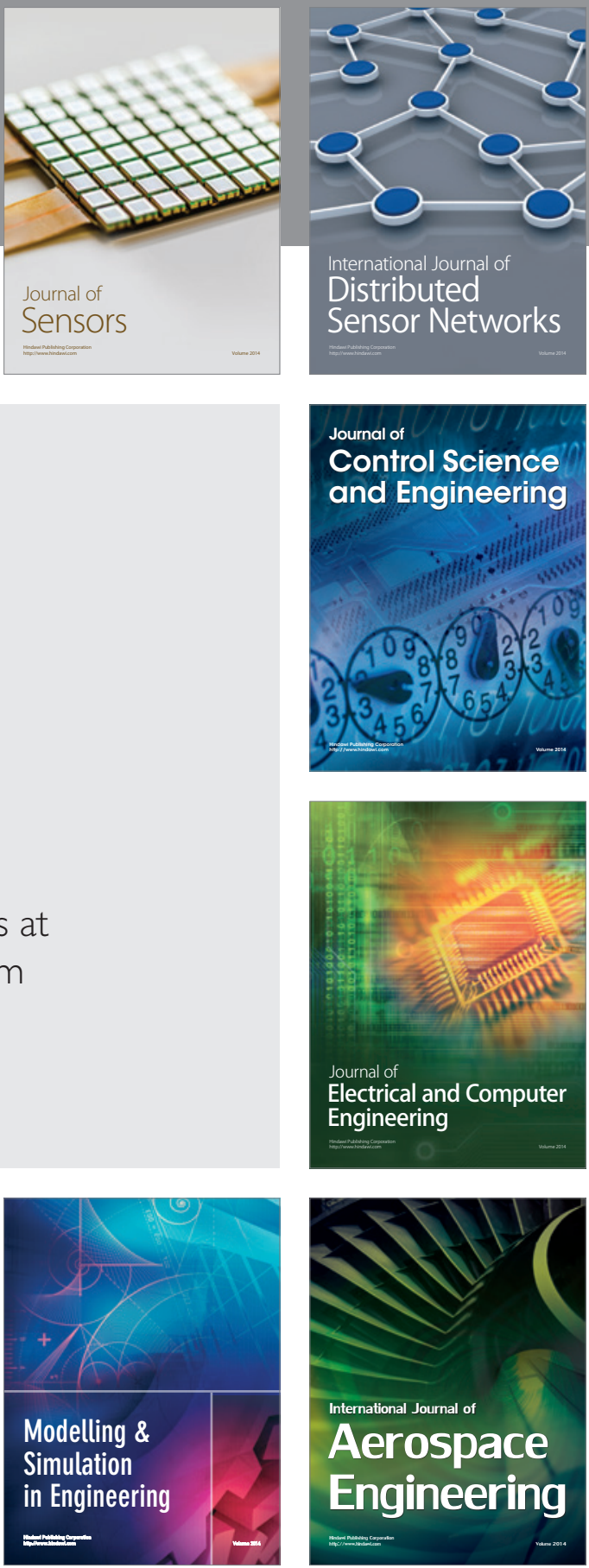

Journal of

Control Science

and Engineering
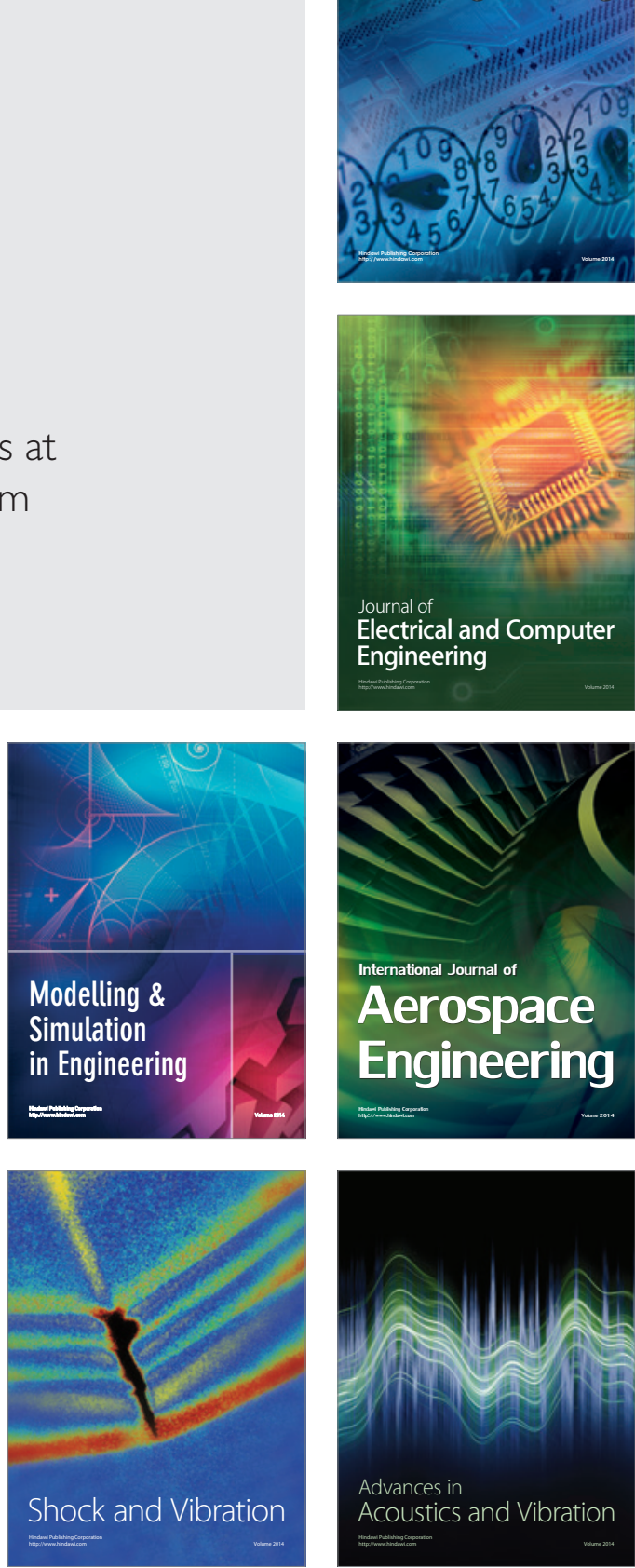